\title{
The Prevalence of Hypertension, Valve Calcification and Left Ventricular Hypertrophy and Geometry in Peritoneal Dialysis Patients
}

\author{
Murvet Yilmaz ${ }^{a}$ Abdulkadir Unsal ${ }^{b}$ Erkan Oztekin ${ }^{c}$ Ozgu Kesmezacar ${ }^{\mathrm{e}}$ \\ Ozlem Harmankaya Kaptanogullari ${ }^{\mathrm{a}}$ Nezaket Eren ${ }^{\mathrm{d}}$ \\ ${ }^{a}$ Nephrology Department, Bakirkoy Dr. Sadi Konuk Training and Research Hospital, and Departments of \\ ${ }^{b}$ Nephrology, ${ }^{c}$ Cardiology and ${ }^{\mathrm{d}}$ Biochemistry, Sisli Etfal Training and Research Hospital, and e Public Health, \\ Istanbul Training and Research Hospital, Istanbul, Turkey
}

\section{Key Words}

Hypertension • Left ventricular hypertrophy · Peritoneal dialysis $\cdot$ Valve calcification

\begin{abstract}
Background/Aims: Cardiac valve calcification (CVC) and left ventricular (LV) abnormalities are common indicators of a poor prognosis in dialysis patients. We determined the prevalence of hypertension, CVC, LV hypertrophy (LVH) and LV geometry in peritoneal dialysis (PD) patients. Methods: Eighty-seven patients (50 female; mean age $42 \pm 13$ years; mean dialysis duration $46 \pm 24$ months) on strict salt and volume restriction, none of whom were receiving antihypertensives, were included in the study. Blood pressure (BP), biochemical parameters, CVC, LVH and LV geometry were determined. Results: Most patients were normotensive. CVC of the mitral and aortic valves and of both valves were noted in 22,23 and $15 \%$ of patients, respectively. Patients with CVC had significantly higher diastolic BP $(p=0.023)$, cardiothoracic index (CTl; $p=0.037$ ) and LV mass index (LVMI; $p=$ 0.002). LVH, noted overall in 44\% of cases, was present in 62 and $36 \%$ of the patients with and without CVC, respectively $(p=0.028)$. Of the whole group, only $50.6 \%$ had normal LV geometry. LVH was associated with lower serum albumin
\end{abstract}

$(p=0.002)$, higher CTI $(p=0.027)$ and more frequent CVC $(p=0.028)$. LVMI was greater in patients with CVC $(p=0.002)$. Conclusion: Strict salt restriction and the achievement of ideal dry weight result in normotension in PD patients. CVC is associated with $\mathrm{LVH}$, both of which are lower in normotensive patients.

Copyright $\odot 2012$ S. Karger AG, Basel

\section{Introduction}

Cardiovascular disease is a major cause of mortality in end-stage renal disease (ESRD) patients. Data from the US Renal Data System (2010) show that deaths attributed to cardiovascular causes are the largest (43\%) contributor to all-cause mortality [1]. Similar figures exist in the registry of the Turkish Society of Nephrology as well; mortality was due to cardiovascular causes in $52 \%$ of the hemodialysis (HD) patients and $47 \%$ of the peritoneal dialysis (PD) cases [2].

Cardiac valve calcification (CVC) is an independent predictor for all-cause and cardiovascular mortality [3]. It is associated with valve dysfunction, myocardial ischemia, conduction defects, infective endocarditis and heart failure [4]. The prevalence of CVC is high (40\%) in

\section{KARGER}

Fax +4161306 1234

E-Mail karger@karger.ch

www.karger.com
(C) 2012 S. Karger AG, Basel

$1420-4096 / 12 / 0356-0431 \$ 38.00 / 0$

Accessible online at:

www.karger.com/kbr
Murvet Yilmaz

Kartaltepe mah. Caglayan sok. No 9/5, Bakirkoy

TR-34710 Istanbul (Turkey)

Tel. +90 5326469726

E-Mail murvetyilmaz@hotmail.com 
ESRD patients [5], and several factors (ageing, dysregulation of mineral metabolism with a high calcium load and the resulting poor calcium/phosphorus balance) have been reported to explain this increased prevalence [6-8]. In addition, there is an association between hypertension and CVC in these patients $[9,10]$.

Left ventricular (LV) hypertrophy (LVH) independently predicts cardiovascular mortality in ESRD patients as well [11]; the prevalence of LVH has been demonstrated in up to $75 \%$ of this patient population [12].

Echocardiography is a simple and also very useful tool for assessing cardiac structure and function noninvasively. According to the LV mass (LVM) and relative wall thickness (RWT), LV geometry may be classified into four groups: normal geometry, concentric remodeling, concentric LVH and eccentric LVH [13].

The combination of fluid overload and hypertension contributes to eccentric and concentric hypertrophy in dialysis patients [14]. In the absence of coronary heart disease, as compared with eccentric LVH, concentric LV geometry characterizes a more severe impairment of the cardiovascular system [15]. Concentric LV geometry is in fact associated with more marked vascular alterations in arterial hypertension as well as in ESRD $[16,17]$ and predicts a more severe outcome $[18,19]$.

Although LVH is quite frequent in HD patients [2023], significant improvement has been noted with strict salt restriction and volume control [20, 24, 25]. Improvement of fluid overload and blood pressure (BP) control may also be achieved in PD patients by rigorous salt restriction and optimization of peritoneal ultrafiltration; consequently, the use of antihypertensive drugs may be abandoned [26].

The aims of the present study were to determine the prevalence of hypertension, CVCs, LVH and geometric patterns in a PD patient population in a single center that applies a strict salt restriction and volume control protocol and to compare the results with those in the literature. We also aimed to determine the most important factors related to the development of CVC and LVH in these patients.

\section{Subjects and Methods}

\section{Study Population}

Eighty-seven patients who had been undergoing PD treatment for more than 3 months were included in the study. Patients with previous myocardial infarction and atrial fibrillation were excluded. The demographic and clinical features of the patients (age, gender, residual urine volume, duration of dialysis, arterial BP and other physical findings), underlying diseases and also features of PD application (daily ultrafiltration, weekly Kt/V urea and total creatinine clearance) were recorded.

\section{BP Measurements}

BP was measured manually using a standard technique with the patient in the sitting position 3 times at 3-min intervals after 10 min of rest, with an Erka sphygmomanometer at regular outpatient follow-up visits; then, the mean of these measurements was calculated. Hypertension was defined as systolic BP $\geq 135$ $\mathrm{mm} \mathrm{Hg}$ and/or diastolic BP $\geq 85 \mathrm{~mm} \mathrm{Hg}$ or current treatment with an antihypertensive drug. For the purpose of this study, furosemide was not categorized as an antihypertensive agent.

\section{Volume Control Protocol}

BP measurements and the cardiothoracic index (CTI) were assumed to be indices of volume status. BP and CTI values were targeted to be below $135 / 85 \mathrm{mmHg}$ and 0.50 , respectively. To reach these targets, a salt-restricted diet $(\mathrm{NaCl}$ intake of 4-5 g/ day) was prescribed by the attending doctors and nurses and the importance of salt restriction and volume control was underlined at every follow-up visit. It was emphasized that water restriction alone is ineffective and also practically impossible as long as salt is not restricted, and it was suggested to the patients that they not drink more than their thirst indicated. In addition to salt restriction, hypertonic PD solutions as necessary were used to achieve dry weight. Furosemide was prescribed to all patients with a urine output of more than $400 \mathrm{ml}$ per day.

\section{Echocardiographic Assessment}

LV end-diastolic diameter, end-systolic diameter, interventricular wall thickness during diastole, posterior wall thickness during diastole and ejection fraction were measured by M-mode echocardiography according to the recommendations of the American Society of Echocardiography [27]. Two-dimensional and M-mode echocardiographic examinations were performed by the same echocardiographer, using a GE Vivid 3 ultrasonoscope with a $2.5-$ to $3.5-\mathrm{MHz}$ transducer at midday after completely emptying the peritoneal dialysate.

CVC was defined as the presence of bright echoes of more than $1 \mathrm{~mm}$ on one or more cusps of the aortic valve, mitral valve or mitral annulus [5].

LVM was calculated according to the Devereux formula [28] indexed for body surface area (LVM index, LVMI). LVH was defined as LVMI $>131 \mathrm{~g} / \mathrm{m}^{2}$ in men and $>100 \mathrm{~g} / \mathrm{m}^{2}$ in women. LV geometry was evaluated based on LVMI and RWT. RWT was calculated by the standard formula, as follows: RWT $=2 \times$ posterior wall thickness/LV end-diastolic diameter [29]; a normal value was assumed to be lower than 0.45 . Concentric LVH was defined as LVH and elevated RWT, while LVH and normal RWT indicated eccentric LVH. Normal LVMI but elevated RWT was defined as concentric remodeling.

\section{Laboratory Measurements}

Serum samples for laboratory analyses were collected on the day of the echocardiographic study. A complete blood count and serum levels of calcium, phosphorus, albumin, total cholesterol, high-density lipoprotein (HDL) and low-density lipoprotein (LDL) cholesterol, triglyceride and intact parathyroid hormone (iPTH) were determined in all patients. When triglyceride levels 
Table 1. Demographic characteristics and clinical/laboratory findings of the patients with and without LVH

\begin{tabular}{|c|c|c|c|c|}
\hline & $\begin{array}{l}\text { All patients } \\
(\mathrm{n}=87)\end{array}$ & $\begin{array}{l}\mathrm{LVH}(+) \\
(\mathrm{n}=38)\end{array}$ & $\begin{array}{l}\mathrm{LVH}(-) \\
(\mathrm{n}=49)\end{array}$ & $\mathrm{p}$ \\
\hline Age, years & $42 \pm 13$ & $43 \pm 13$ & $40 \pm 13$ & NS \\
\hline Female/male, $\mathrm{n}$ & $50 / 37$ & $17 / 21$ & $20 / 29$ & NS \\
\hline Duration of PD, months & $46 \pm 24$ & $47 \pm 29$ & $44 \pm 19$ & NS \\
\hline Anuric patients, $\%$ & 65.5 & 44 & 56 & NS \\
\hline Daily urine volume, $\mathrm{ml}$ & $145 \pm 278$ & $149 \pm 305$ & $143 \pm 259$ & NS \\
\hline Daily total ultrafiltration, $\mathrm{ml}$ & $1,121 \pm 420$ & $1,055 \pm 423$ & $1,172 \pm 414$ & NS \\
\hline $\mathrm{Kt} / \mathrm{V}$ urea, weeks & $2.3 \pm 0.6$ & $2.1 \pm 0.3$ & $2.4 \pm 0.7$ & NS \\
\hline Creatinine clearance, $1 /$ week $/ 1.73 \mathrm{~m}^{2}$ & $67 \pm 27$ & $60 \pm 10$ & $71 \pm 33$ & NS \\
\hline Patients on $3.86 / 4.25 \%$ dextrose, $\%$ & 19.5 & 24 & 16 & NS \\
\hline Weekly $3.86 / 4.25 \%$ dextrose, liters & $4.4 \pm 10.4$ & $6.7 \pm 14$ & $2.6 \pm 6.1$ & NS \\
\hline Systolic BP, mm Hg & $108 \pm 22$ & $111 \pm 23$ & $105 \pm 20$ & NS \\
\hline Diastolic BP, mm Hg & $68 \pm 13$ & $71 \pm 14$ & $66 \pm 12$ & NS \\
\hline Ejection fraction, $\%$ & $65 \pm 9$ & $63 \pm 12$ & $66 \pm 6$ & NS \\
\hline CTI & $0.47 \pm 0.06$ & $0.48 \pm 0.05$ & $0.46 \pm 0.06$ & 0.027 \\
\hline CVC, $\%$ & 30 & 42 & 20 & 0.028 \\
\hline LVMI, $\mathrm{g} / \mathrm{m}^{2}$ & $115 \pm 44$ & $150 \pm 43$ & $88 \pm 21$ & 0.000 \\
\hline Hemoglobin, g/dl & $11.4 \pm 1.6$ & $11.3 \pm 1.7$ & $11.5 \pm 1.5$ & NS \\
\hline \multicolumn{5}{|l|}{ Serum } \\
\hline Albumin, g/dl & $3.7 \pm 0.4$ & $3.6 \pm 0.3$ & $3.9 \pm 0.4$ & 0.002 \\
\hline Calcium, mg/dl & $9.2 \pm 0.7$ & $9.1 \pm 0.7$ & $9.3 \pm 0.7$ & NS \\
\hline Phosphorus, mg/dl & $4.8 \pm 1.2$ & $5.1 \pm 1.5$ & $4.7 \pm 0.9$ & NS \\
\hline $\mathrm{iPTH}, \mathrm{pg} / \mathrm{ml}$ & $503 \pm 403$ & $525 \pm 421$ & $486 \pm 392$ & NS \\
\hline Triglyceride, $\mathrm{mg} / \mathrm{dl}$ & $216 \pm 117$ & $231 \pm 134$ & $204 \pm 102$ & NS \\
\hline Total cholesterol, mg/dl & $199 \pm 47$ & $197 \pm 61$ & $200 \pm 34$ & NS \\
\hline HDL cholesterol, mg/dl & $42 \pm 12$ & $41 \pm 13$ & $44 \pm 11$ & NS \\
\hline LDL cholesterol, mg/dl & $114 \pm 41$ & $111 \pm 49$ & $116 \pm 33$ & NS \\
\hline
\end{tabular}

were lower than $400 \mathrm{mg} / \mathrm{dl}$, LDL cholesterol levels were calculated according to the Friedewald formula [30]:

LDL cholesterol $=$ total cholesterol $-[($ triglycerides $/ 5)+\mathrm{HDL}$ cholesterol].

Teleradiography was performed on an upright frontal view of the chest at $2 \mathrm{~m}$ during quiet breathing, and the CTI was calculated by the following formula: $\mathrm{CTI}=(\mathrm{MRD}+\mathrm{MLD}) / \mathrm{ID}$, where ID is the internal diameter of the chest at the level of the right hemidiaphragm, MRD is the greatest perpendicular diameter from midline to the right heart border and MLD is the greatest perpendicular diameter from midline to the left heart border.

\section{Statistical Analysis}

Results were given as means \pm SD or proportions. Continuous variables were compared using Student's t test or the MannWhitney U test. Statistical analysis of discrete variables was performed by the $\chi^{2}$ test. Correlations were expressed by Pearson's correlation coefficient. The level of significance was accepted as $\mathrm{p}<0.05$. Epi Info version 3.5.3 was used for statistical analysis.

Prevalence of Valve Calcification and LVH in Peritoneal Dialysis Patients

\section{Results}

Of the 87 patients, 37 were males and 50 females. The mean age was $42 \pm 13$ years (range 18-73), and the mean time on PD was $46 \pm 24$ months (range 6-128). Dialysis duration was shorter than 1 year in 4 patients $(5 \%)$ and longer than 5 years in $14(16 \%)$; this duration was between 1 and 2 years in 12 patients (14\%) and 2 and 5 years in 57 $(66 \%)$

Demographic features of the patients as well as some clinical and laboratory findings are provided in table 1 . Etiologies of renal diseases were as follows: diabetic nephropathy $(n=16)$, primary glomerular diseases $(n=14)$, hypertensive nephrosclerosis $(n=6)$, other causes $(n=9)$ and undetermined etiology $(\mathrm{n}=42)$.

Thirty patients $(34.5 \%)$ were on automated PD treatment, while 57 (65.5\%) were under conventional continuous ambulatory PD with different protocols. Fifty-seven 
Table 2. Characteristics of the patients with and without CVCs

\begin{tabular}{lccl}
\hline & $\begin{array}{c}\text { CVC (+) } \\
(\mathrm{n}=26)\end{array}$ & $\begin{array}{c}\text { CVC }(-) \\
(\mathrm{n}=61)\end{array}$ & $\mathrm{p}$ \\
\hline Age, years & $46 \pm 15$ & $40 \pm 11$ & $\mathrm{NS}$ \\
Female/male, $\mathrm{n}$ & $12 / 14$ & $38 / 23$ & $\mathrm{NS}$ \\
Duration of PD, months & $51 \pm 27$ & $46 \pm 23$ & $\mathrm{NS}$ \\
Systolic BP, mm Hg & $114 \pm 25$ & $105 \pm 19$ & $\mathrm{NS}$ \\
Diastolic BP, mm Hg & $73 \pm 15$ & $66 \pm 12$ & 0.023 \\
CTI & $0.49 \pm 0.00$ & $0.46 \pm 0.00$ & 0.037 \\
Ejection fraction, \% & $63 \pm 11$ & $65 \pm 8$ & $\mathrm{NS}$ \\
LVMI, g/m ${ }^{2}$ & $142 \pm 57$ & $104 \pm 32$ & 0.002 \\
LVH, \% & 62 & 36 & 0.028 \\
Albumin, g/dl & $3.6 \pm 0.3$ & $3.8 \pm 0.4$ & 0.037 \\
Calcium, mg/dl & $9.3 \pm 0.7$ & $9.2 \pm 0.7$ & $\mathrm{NS}$ \\
Phosphorus, mg/dl & $5.1 \pm 1.2$ & $4.7 \pm 1.2$ & NS \\
Calcium $\times$ phosphorus & & & \\
$\quad$ (mg/dl) & & & \\
iPTH, pg/ml & $46.8 \pm 10.2$ & $43.9 \pm 11.7$ & $\mathrm{NS}$ \\
Triglyceride, mg/dl & $520 \pm 541$ & $496 \pm 332$ & NS \\
Total cholesterol, mg/dl & $204 \pm 111$ & $221 \pm 121$ & $\mathrm{NS}$ \\
HDL cholesterol, mg/dl & $196 \pm 48$ & $200 \pm 47$ & NS \\
LDL cholesterol, mg/dl & $43 \pm 16$ & $42 \pm 10$ & NS \\
Hemoglobin, g/dl & $113 \pm 35$ & $114 \pm 43$ & NS \\
\hline
\end{tabular}

NS = Not significant.

patients $(65.5 \%)$ were anuric. Daily total ultrafiltration volume was $1,121 \pm 420 \mathrm{ml}$; this volume was 1,108 \pm 430 and $1,189 \pm 365 \mathrm{ml}$ in the patients who had received PD for less and more than 5 years, respectively $(p=0.411)$. The quantity of ultrafiltration in anuric patients $(1,108 \pm$ $435 \mathrm{ml})$ and in patients with some urine output $(1,145 \pm$ $393 \mathrm{ml})$ was also not significantly different $(\mathrm{p}=0.704)$.

Overall, $83 \%$ of the patients were using calcium-containing phosphate binders, and $61 \%$ of the patients were receiving vitamin $\mathrm{D}$ preparations.

BP was well controlled in most of the patients; 12 patients (14\%) were hypertensive. None of the patients received any antihypertensive drugs, except furosemide. The percentage of patients with CTI $\geq 0.5$ was $33 \%$.

Overall, CVCs were found in 26 of the 87 patients (30\%); mitral CVC was present in 19 (22\%), aortic CVC in $20(23 \%)$ and both in $13(15 \%)$. The clinical characteristics of patients with and without CVCs are presented in table 2 . No significant differences were found with regard to age, gender, PD duration, systolic BP, calcium, phosphorus, $\mathrm{PTTH}$, lipids and hemoglobin values between these two groups. Patients with CVC had significantly higher diastolic BP, CTI and LVMI and lower serum albumin. $\mathrm{LVH}$ was found in $62 \%$ of the patients with $\mathrm{CVC}$
Table 3. Correlation analyses between LVMI and various clinical and laboratory parameters (only the significant correlations have been provided)

\begin{tabular}{lrl}
\hline & \multicolumn{1}{c}{$\mathrm{r}$} & $\mathrm{p}$ \\
\hline Albumin & -0.256 & 0.017 \\
Systolic BP & 0.313 & 0.003 \\
Diastolic BP & 0.329 & 0.002 \\
CTI & 0.289 & 0.007 \\
Ejection fraction & -0.396 & 0.000 \\
Weekly 3.86/4.25\% dextrose usage & 0.334 & 0.002 \\
\hline
\end{tabular}

but only in 36\% without CVC. LVMI was $142 \pm 57$ and $104 \pm 32 \mathrm{~g} / \mathrm{m}^{2}$ in patients with and without CVC, respectively $(\mathrm{p}=0.002)$. Patients with mitral and aortic CVCs had LVMI of $151 \pm 61$ and $147 \pm 62 \mathrm{~g} / \mathrm{m}^{2}$, respectively. Patients with both mitral and aortic CVCs had the highest LVMI $\left(163 \pm 66 \mathrm{~g} / \mathrm{m}^{2} ; \mathrm{p}=0.01\right)$

LVH was diagnosed in 38 patients (44\%); most of these (32.2\%) had eccentric LVH. Concentric remodeling and concentric LVH were identified in $5(5.7 \%)$ and 10 patients (11.5\%), respectively. The ejection fraction was found to be $65 \pm 9 \%$ in the whole group; it was less than $50 \%$ in only 3 patients (3.4\%).

Comparison of various parameters in patients with and without LVH is provided in table 1 . Age, gender, duration of $\mathrm{PD}$, proportion of anuric patients, daily urine volume, daily ultrafiltration volume, Kt/V urea weekly, creatinine clearance, ejection fraction, systolic and diastolic BP were not significantly different between the two groups. On the other hand, CTI and the proportion of patients with CVCs were higher in the group with LVH. Also, serum albumin was significantly lower in the LVH group.

LVMI was significantly correlated with serum albumin, systolic BP, diastolic BP, CTI, ejection fraction and weekly hypertonic solution (3.86/4.25\% dextrose) usage (table 3), while it did not show any significant correlation with age, dialysis duration, calcium, phosphorus, iPTH, triglyceride, total cholesterol, HDL and LDL cholesterol or hemoglobin values.

\section{Discussion}

Cardiovascular diseases are the most frequent cause of mortality in patients with ESRD. Hypertension-associated CVC and LVH are independent predictors of cardio- 
vascular mortality and have frequently been noted in $\mathrm{PD}$ patients $[3,21,31,32]$. We therefore aimed to investigate the prevalence of these risk factors in our PD patient population.

Abnormalities in LV size and function are common in dialysis patients due to a variety of reasons such as volume overload, anemia, secondary hyperparathyroidism and serum albumin [33]. BP is considered one of the main determinants of $\mathrm{LVH}$ in chronic renal disease, and strategies to decrease BP have been shown to exert a beneficial effect on LVMI. There is growing evidence that PD patients are often volume expanded and have high BP associated with LVH $[14,34]$.

According to the registry data of the Turkish Society of Nephrology, the prevalence of hypertension is quite high (66.5\%) in PD patients [2]. In a single-center study, associations among BP, volume status and cardiac hypertrophy in 74 patients on continuous ambulatory PD were investigated [32]. Ambulatory BP monitoring was used to observe the course of BP. The prevalence of hypertension was found to be $82 \%$, which was uncontrolled even by the use of antihypertensive drugs in 54 patients (73\%). Similarly, in a cross-sectional study of 504 patients on longterm PD (average duration of treatment 32 months), the prevalence of hypertension was found to be $88 \%$ [35]. All these studies indicate that hypertension is a frequent complication in PD patients.

However, some other studies have shown that excellent $\mathrm{BP}$ control can be achieved in this patient population by strict volume control, without the use of any antihypertensive drugs $[26,36]$. This was achieved not only in the short term, but also in the long run [36]. In our study, most of the patients (86\%) had normal BP without using any antihypertensive drugs as well. This favorable result could be achieved by rigorous salt restriction and optimization of peritoneal ultrafiltration. Duration on PD or urine production were not associated with ultrafiltration volume. Euvolemia could be achieved by using hypertonic PD solutions and also strict salt restriction, which was made possible by long hours of patient education. We should underline that in the present study, most of the patients had been on dialysis for quite a long time; $82 \%$ of the patients had been on PD treatment for more than 2 years. This observation is consistent with a previous report underlining satisfactory $\mathrm{BP}$ control in PD patients in the short and long term [36].

Soft-tissue calcifications, including CVCs, are common in both HD and PD patients; a prevalence of up to $50 \%$ [9] has been reported in the HD population. Specifically, prevalences of 44.5 and $52 \%$ of mitral and aortic calcification, respectively, were described in HD patients [10], while mitral CVC was found in $44 \%$ of PD patients and aortic CVC in 34\% [37].

Multiple risk factors may predispose these patients to CVC. Among these, mineral metabolism deserves special mention $[5,38,39]$. In a single-center study it was reported that increased $\mathrm{Ca} \times \mathrm{P}$ product was a significant risk factor for mitral but not aortic CVC [10, 37]; however, this association has not been confirmed in all studies [3]. The role of PTH in CVCs is controversial as well; it has been noted that serum calcium and PTH but not phosphorus levels were associated with a higher risk in patients with mitral CVC [4]. However, several other studies did not confirm any relation between PTH and CVCs $[10,40]$. In our study, no significant difference was found with regard to serum calcium, phosphorus and $\mathrm{PTH}$ values in the patients with and without CVCs.

Among the risk factors for CVC, hypertension deserves special mention; it may play a pathogenic role due to increased mechanical stress [39]. Previous studies have reported that a history of hypertension before starting dialysis was associated with a high risk of CVC $[9,10,41]$, and vigorous control of $\mathrm{BP}$ is vital to prevent this complication [5]. CVCs were also found to be associated with $\mathrm{LVH}$, particularly in patients with both (mitral and aortic) CVCs [42]. In HD patients, CVC is associated with increased arterial stiffness and results in increased afterload connected with LVH [42]. In PD patients, however, it is not clear how CVC is associated with LVH. In our PD patients, the prevalence of CVCs was lower than in other studies; this abnormality was associated with LVMI, particularly in patients with both (mitral and aortic) CVCs. This favorable finding with regard to CVC is most probably due to strict volume and BP control.

In adult chronic dialysis patients, the prevalence of LVH was noted to be as high as $75 \%[12,43]$. In a crosssectional echocardiographic study on 69 patients who had been on PD for more than 12 months, only 10 of the patients (14\%) had normal LV geometry, and the most frequent abnormality was eccentric LVH (46\%), followed by concentric LVH (28\%) [13]. Similarly, in another study, $86.4 \%$ of the patients overall had LVH; among these, $56.3 \%$ had concentric LVH, 30.1\% had eccentric LVH, $6.8 \%$ had concentric remodeling and only $6.8 \%$ of the patients had normal LV geometry [33]. In our PD patients, the prevalence of $\mathrm{LVH}$ was $44 \%$, which is a significantly lower figure than in the literature $[12,13,33,43]$. The cause of this favorable outcome is obscure, but most probably satisfactory volume and BP control played a central role. 
Hypoalbuminemia has been suggested to be an independent risk factor for progressive LVH [12, 33, 44]. The biological basis of a possible adverse effect of hypoalbuminemia on cardiac structure and function is unclear [45]. Serial albumin levels were found to be inversely associated with the progression of LV dilation, especially in PD patients [45]. In the present study, serum albumin was significantly lower in the LVH group, which can be explained by hypervolemia-induced dilution.

Hypoalbuminemia is also a major risk factor for mortality in ESRD patients [45], and an important link between inflammation and CVC in PD patients has been reported [46]. The presence of inflammation and malnutrition (as compared with no evidence of inflammation or malnutrition) was associated with at least a doubling in the prevalence of CVC [47]. In our study, patients with CVC had significantly lower serum albumin; however, a drawback of the present study was that serum C-reactive protein levels were not available.
Our study had several limitations. Firstly, salt intake could not be measured objectively. Also, it lacked a control group; our ethical consideration of not leaving patients with the risks of volume overload prevented the inclusion of such a group.

In conclusion, in PD patients, excellent BP control can be achieved by strict salt restriction and volume control, without the use of any antihypertensive drugs. CVC is associated with $\mathrm{LVH}$; this association becomes even more significant when both mitral and aortic valves are involved at the same time. CVC and $\mathrm{LVH}$ prevalence are lower in patients who have normal BP with appropriate volume control.

\section{Disclosure Statement}

No disclosures.

\section{References}

1 US Renal Data System: USRDS 2010 Annual Data Report. Atlas of Chronic Kidney Disease and End-Stage Renal Disease in the United States. Bethesda, National Institutes of Health, National Institute of Diabetes and Digestive and Kidney Diseases, 2010.

2 Serdengeçti K, Suleymanlar G, Altiparmak MR, Seyahi N: Registry of Nephrology, Dialysis and Transplantation in Turkey - Registry 2009. Istanbul, Turkish Society of Nephrology, 2010.

-3 Panuccio V, Tripepi R, Tripepi G, Mallamaci F, Benedetto FA, Cataliotti A, Bellanuova I, Giacone G, Malatino LS, Zoccali C: Heart valve calcifications, survival, and cardiovascular risk in hemodialysis patients. Am J Kidney Dis 2004;43:479-484.

4 Mazzaferro S, Coen G, Bandini S, Borgatti PP, Ciaccheri M, Diacinti D, Ferranti E, Lusenti T, Mancini G, Monducci I, et al: Role of ageing, chronic renal failure and dialysis in the calcification of mitral annulus. Nephrol Dial Transplant 1993;8:335-340.

5 Tarrass F, Benjelloun M, Zamd M, Medkouri G, Hachim K, Benghanem MG, Ramdani B: Heart valve calcifications in patients with end-stage renal disease: analysis for risk factors. Nephrology (Carlton) 2006;11:494496.

6 Raine AE: Acquired aortic stenosis in dialysis patients. Nephron 1994;68:159-168.

7 Guérin AP, London GM, Marchais SJ, Metivier F: Arterial stiffening and vascular calcifications in end-stage renal disease. Nephrol Dial Transplant 2000;15:1014-1021.
8 Wang AY, Ho SS, Wang M, Liu EK, Ho S, Li PK, Lui SF, Sanderson JE: Cardiac valvular calcification as a marker of atherosclerosis and arterial calcification in end-stage renal disease. Arch Intern Med 2005;165:327332.

-9 Braun J, Oldendorf M, Moshage W, Heidler R, Zeitler E, Luft FC: Electron beam computed tomography in the evaluation of cardiac calcification in chronic dialysis patients. Am J Kidney Dis 1996;27:394-401.

10 Ribeiro S, Ramos A, Brandão A, Rebelo JR, Guerra A, Resina C, Vila-Lobos A, Carvalho F, Remédio F, Ribeiro F: Cardiac valve calcification in haemodialysis patients: role of calcium-phosphate metabolism. Nephrol Dial Transplant 1998;13:2037-2040.

11 London GM, Pannier B, Guerin AP, Blacher J, Marchais SJ, Darne B, Metivier F, Adda H, Safar ME: Alterations of left ventricular hypertrophy in and survival of patients receiving hemodialysis: follow-up of an interventional study. J Am Soc Nephrol 2001;12: 2759-2767.

12 Foley RN, Parfrey PS, Harnett JD, Kent GM, Martin CJ, Murray DC, Barre PE: Clinical and echocardiographic disease in patients starting end-stage renal disease therapy. Kidney Int 1995;47:186-192.

13 Toprak A, Koc M, Tezcan H, Ozener IC, Akoglu E, Oktay A: Inferior vena cava diameter determines left ventricular geometry in continuous ambulatory peritoneal dialysis patients: an echocardiographic study. Nephrol Dial Transplant 2003;18:2128-2133.
14 Ates K: Salt and water in PD: the Turkish contribution. Perit Dial Int 2008;28:224228 .

15 de Simone G: Left ventricular geometry and hypotension in end-stage renal disease: a mechanical perspective. J Am Soc Nephrol 2003;14:2421-2427.

16 Roman MJ, Pickering TG, Schwartz JE, Pini R, Devereux RB: Relation of arterial structure and function to left ventricular geometric patterns in hypertensive adults. J Am Coll Cardiol 1996;28:751-756.

17 London GM, Guerin AP, Marchais SJ, Pannier B, Safar ME, Day M, Metivier F: Cardiac and arterial interactions in end-stage renal disease. Kidney Int 1996;50:600-608.

18 Koren MJ, Devereux RB, Casale PN, Savage DD, Laragh JH: Relation of left ventricular mass and geometry to morbidity and mortality in uncomplicated essential hypertension. Ann Intern Med 1991;114:345-352.

19 Verdecchia P, Schillaci G, Borgioni C, Ciucci A, Battistelli M, Bartoccini C, Santucci A, Santucci C, Reboldi G, Porcellati C: Adverse prognostic significance of concentric remodeling of the left ventricle in hypertensive patients with normal left ventricular mass. J Am Coll Cardiol 1995;25:871-878.

20 Ozkahya M, Ok E, Cirit M, Aydin S, Akçiçek F, Başçi A, Dorhout Mees EJ: Regression of left ventricular hypertrophy in haemodialysis patients by ultrafiltration and reduced salt intake without antihypertensive drugs. Nephrol Dial Transplant 1998;13:14891493. 
21 Parfrey PS, Foley RN, Harnett JD, Kent GM, Murray DC, Barre PE: Outcome and risk factors for left ventricular disorders in chronic uraemia. Nephrol Dial Transplant 1996;11: 1277-1285.

22 Foley RN, Curtis BM, Randell EW, Parfrey PS: Left ventricular hypertrophy in new hemodialysis patients without symptomatic cardiac disease. Clin J Am Soc Nephrol 2010; 5:805-813.

23 Nitta K, Akiba T, Uchida K, Otsubo S, Otsubo Y, Takei T, Ogawa T, Yumura W, Kabaya T, Nihei $\mathrm{H}$ : Left ventricular hypertrophy is associated with arterial stiffness and vascular calcification in hemodialysis patients. Hypertens Res 2004;27:47-52.

-24 Ozkahya M, Töz H, Unsal A, Ozerkan F, Asci G, Gürgün C, Akçiçek F, Mees EJ: Treatment of hypertension in dialysis patients by ultrafiltration: role of cardiac dilatation and time factor. Am J Kidney Dis 1999;34:218-221.

-25 Ozkahya M, Toz H, Qzerkan F, Duman S, Ok E, Basci A, Mees EJ: Impact of volume control on left ventricular hypertrophy in dialysis patients. J Nephrol 2002;15:655-660.

26 Gunal AI, Duman S, Ozkahya M, Töz H, Asçi G, Akcicek F, Basci A: Strict volume control normalizes hypertension in peritoneal dialysis patients. Am J Kidney Dis 2001; 37:588-593.

-27 Sahn DJ, DeMaria A, Kisslo J, Weyman A: Recommendations regarding quantitation in M-mode echocardiography: results of a survey of echocardiographic measurements. Circulation 1978;58:1072-1083.

28 Devereux RB, Alonso DR, Lutas EM, Gottlieb GJ, Campo E, Sachs I, Reichek N: Echocardiographic assessment of left ventricular hypertrophy: comparison to necropsy findings. Am J Cardiol 1986;57:450-458.

-29 Ganau A, Devereux RB, Roman MJ, de Simone G, Pickering TG, Saba PS, Vargiu P, Simongini I, Laragh JH: Patterns of left ventricular hypertrophy and geometric remodeling in essential hypertension. J Am Coll Cardiol 1992;19:1550-1558.
Friedewald WT, Levy RI, Fredrickson DS: Estimation of the concentration of low-density lipoprotein cholesterol in plasma, without use of the preparative ultracentrifuge. Clin Chem 1972;18:499-502.

31 Ateş K, Nergizoğlu G, Keven K, Sen A, Kutlay S, Ertürk S, Duman N, Karatan O, Ertuğ AE: Effect of fluid and sodium removal on mortality in peritoneal dialysis patients. Kidney Int 2001;60:767-776.

32 Koc M, Toprak A, Tezcan H, Bihorac A, Akoglu E, Ozener IC: Uncontrolled hypertension due to volume overload contributes to higher left ventricular mass index in CAPD patients. Nephrol Dial Transplant 2002;17: 1661-1666.

33 Covic A, Mardare NG, Ardeleanu S, Prisada O, Gusbeth-Tatomir P, Goldsmith DJ: Serial echocardiographic changes in patients on hemodialysis: an evaluation of guideline implementation. J Nephrol 2006;19:783-793.

34 Enia G, Mallamaci F, Benedetto FA, Panuccio V, Parlongo S, Cutrupi S, Giacone G, Cottini E, Tripepi G, Malatino LS, Zoccali C: Long-term CAPD patients are volume expanded and display more severe left ventricular hypertrophy than haemodialysis patients. Nephrol Dial Transplant 2001;16: 1459-1464.

35 Cocchi R, Degli Esposti E, Fabbri A, Lucatello A, Sturani A, Quarello F, Boero R, Bruno M, Dadone C, Favazza A, Scanziani R, Tommasi A, Giangrande A: Prevalence of hypertension in patients on peritoneal dialysis: results of an Italian multicentre study. Nephrol Dial Transplant 1999;14:1536-1540.

36 Asci G, Ozkahya M, Duman S, Toz H, Erten $S$, Ok E: Volume control associated with better cardiac function in long-term peritoneal dialysis patients. Perit Dial Int 2006;26:8588.

37 Hüting J: Mitral valve calcification as an index of left ventricular dysfunction in patients with end-stage renal disease on peritoneal dialysis. Chest 1994;105:383-388.

38 Rufino M, García S, Jiménez A, Alvarez A, Miquel R, Delgado P, Marrero D, Torres A, Hernández D, Lorenzo V: Heart valve calcification and calcium $\mathrm{x}$ phosphorus product in hemodialysis patients: analysis of optimum values for its prevention. Kidney Int Suppl 2003;85:115-118.
39 Maher ER, Young G, Smyth-Walsh B, Pugh S, Curtis JR: Aortic and mitral valve calcification in patients with end-stage renal disease. Lancet 1987;ii:875-877.

40 Covic A, Goldsmith DJ, Georgescu G, Venning MC, Ackrill P: Echocardiographic findings in long-term, long-hour hemodialysis patients. Clin Nephrol 1996;45:104-110.

41 Yoshida M, Takamatsu J, Yoshida S, Tanaka K, Takeda K, Higashi H, Kitaoka H, Ohsawa $\mathrm{N}$ : Scores of coronary calcification determined by electron beam computed tomography are closely related to the extent of diabetes-specific complications. Horm Metab Res 1999;31:558-563.

-42 Strózecki P, Odrowaz-Sypniewska G, Manitius J: Cardiac valve calcifications and left ventricular hypertrophy in hemodialysis patients. Ren Fail 2005;27:733-738.

43 Paoletti E, Cassottana P, Bellino D, Specchia C, Messa P, Cannella G: Left ventricular geometry and adverse cardiovascular events in chronic hemodialysis patients on prolonged therapy with ACE inhibitors. Am J Kidney Dis 2002;40:728-736.

44 Moon KH, Song IS, Yang WS, Shin YT, Kim SB, Song JK, Park JS: Hypoalbuminemia as a risk factor for progressive left-ventricular hypertrophy in hemodialysis patients. Am J Nephrol 2000;20:396-401.

45 Foley RN, Parfrey PS, Harnett JD, Kent GM, Murray DC, Barre PE: Hypoalbuminemia, cardiac morbidity, and mortality in endstage renal disease. J Am Soc Nephrol 1996; 7:728-736.

46 Wang AY, Woo J, Wang M, Sea MM, Ip R, Li PK, Lui SF, Sanderson JE: Association of inflammation and malnutrition with cardiac valve calcification in continuous ambulatory peritoneal dialysis patients. J Am Soc Nephrol 2001;12:1927-1936.

47 Wang AY: Vascular and other tissue calcification in peritoneal dialysis patients. Perit Dial Int 2009;29:9-14.
Prevalence of Valve Calcification and LVH in Peritoneal Dialysis Patients 